\title{
Is emergency cesarean section more risky than elective cesarean section in women with previous cesarean section?
}

\author{
Balwan Singh Dhillon ${ }^{1 *}$, Nomita Chandhiok ${ }^{2}$, M. Vishnu Vardhana Rao ${ }^{3}$
}

\author{
${ }^{1}$ Scientist-F, ${ }^{2}$ Scientist-G, Indian Council of Medical Research, Ansari Nagar, New Delhi, India \\ ${ }^{3}$ Director, ICMR-National Institute of Medical Statistics, Ansari Nagar, New Delhi, India
}

Received: 07 March 2018

Accepted: 03 April 2018

\section{*Correspondence:}

Mr. Balwan Singh Dhillon,

E-mail: balwandhillon@gmail.com

Copyright: (c) the author(s), publisher and licensee Medip Academy. This is an open-access article distributed under the terms of the Creative Commons Attribution Non-Commercial License, which permits unrestricted non-commercial use, distribution, and reproduction in any medium, provided the original work is properly cited.

\begin{abstract}
Background: Cesarean section is one of the most performed surgical procedures all over the world, but unfortunately cesarean sections are associated with a great deal of maternal morbidity and mortality. In the past the rate of cesarean section has increased for many avoidable and unavoidable indications both in developed and developing countries. The objective of this study was to compare maternal morbidity and mortality in elective repeat cesarean section (ElRCS) and emergency repeat cesarean section Em-RCS.

Methods: Prospective data was recorded on management practices, associated complications and morbidity and mortality on 15664 consecutive cases of previous cesarean section reporting at 30 medical colleges/teaching hospitals for delivery.

Results: Of the 15664 women with a previous cesarean section, 5399 (34.5\%) women underwent elective repeat cesarean section, $7752(49.5 \%)$ women who underwent emergency repeat cesarean section and $2513(16.0 \%)$ had successful trial of labor (S-TOL). There was failed trial of labor (F-TOL) in 1522 cases and requiring an emergency cesarean section for delivery of baby. Therefore, total no. of 7752 women had an emergency cesarean section. The overall maternal morbidity was $22.5 \%, 20.7 \%$ in Em-RCS and El-RCS respectively. Blood loss was more than $1000 \mathrm{ml}$ in $7.2 \%$ of Em-RCS where as in El-RCS it was $8.8 \%$, blood transfusion was $7.5 \%$ in Em-RCS where as it was $6.5 \%$ in El-RCS, dehiscence of scar in Em-RCS was $4.7 \%$ as compared to $2.2 \%$ in El-RCS, uterine rupture was $1.2 \%$ in Em-RCS as compared to $0.7 \%$ in El-RCS found statistically significant. Post-operative complication was $5.9 \%$ cases in Em-RCS where as in El-RCS was $5.8 \%$ ( $\mathrm{p}=0.79$ non-significant). Maternal mortality was reported in 12 $(0.2 \%)$ cases of Em-RCS as compared to $5(0.1 \%)$ cases in El-RCS $(\mathrm{p}=0.37)$ which was not statistically significant.

Conclusions: Maternal morbidity was found more in emergency repeat cesarean section than in elective repeat cesarean section. Complications and referral of women who are likely to undergo cesarean section should be diagnosed at an early stage so that the maternal morbidity and mortality can be prevented.
\end{abstract}

Keywords: Emergency repeat cesarean section, Elective repeat cesarean section, Maternal, Morbidity, Mortality

\section{INTRODUCTION}

A cesarean section is a surgical procedure in which incisions are made through woman's abdomen and uterus to deliver her baby after 20 weeks of gestational age. Caesarean section is a lifesaving procedure done where vaginal delivery is considered dangerous to either the baby or mother. When the access to obstetric care is growing, there has been a concern over rising rates of cesarean section in the world. ${ }^{1}$ Over the past 30 years the rate of cesarean section has increased from 5\% to more than $20 \%$ the reason being, avoidance of mid-forceps and vaginal breech deliveries, use of foetal monitoring during labor and the belief that cesarean section will reduce 
perinatal mortality. ${ }^{2}$ This rate of cesarean section has been increasing and continue in future. Cesarean section can be done as an elective as well as emergency procedure.

Elective cesarean section is a term used when the procedure is done at a pre-arranged time during pregnancy to ensure the best quality of obstetrics, anesthesia, neonatal resuscitation and nursing services.

The procedure is termed as emergency caesarean section when it is performed due to unforeseen or acute obstetric emergencies. $^{3}$

It has been seen that morbidity and mortality are associated more with emergency procedures than elective procedures. ${ }^{4,5}$

With this background the study was conducted to study maternal morbidity and mortality in elective and emergency caesarean sections at tertiary care teaching hospitals in India.

\section{METHODS}

The Indian Council of Medical Research (ICMR) has a network of Human Reproduction Research Centre (HRRC) located in the department of obstetrics and gynecology of 30 medical colleges/teaching hospitals in various parts of the country.

Prospective data was recorded through proforma on management practices, associated complications and mortality for a period of 8 months in 2005-2006 on 15664 consecutive cases of previous cesarean section reporting at 30 medical colleges/teaching hospitals for delivery.

Information on the patient's characteristics including age, parity, booked, referred, past obstetric medical and surgical history, history of present pregnancy and complication was collected.

The mode of delivery was recorded as VBAC (vaginal birth after caesarean), elective cesarean section or emergency cesarean section. Maternal complications developed during or after the labor was noted e.g. uterine rupture, blood transfusion, hysterectomy scar tenderness, scar dehiscence etc.

The women were followed up from admission to discharge from the hospital. The data collected were coded and fed into the computer using Epi-Info.

Statistical analysis was performed using SPSS V 19.0 for windows and various descriptive statistics were used to calculate frequencies, percentages, means and standard deviation. Chi square test were used for the comparison.

\section{RESULTS}

Of the 15664 women with a previous cesarean section, $5399(34.5 \%)$ women underwent elective repeat cesarean section, $6230(39.8 \%)$ women underwent emergency repeat cesarean section, $2513(16.0 \%)$ had successful trial of labor (S-TOL).

There was failed trial of labor (F-TOL) in 1522 cases and requiring an emergency cesarean section for delivery of baby. Therefore, a total number of 7752 (49.5\%) women had an Em-RCS.

Mean age of women who had emergency repeat cesarean section was $25.9 \pm 3.9$ years. The value for those who had elective repeat cesarean section was $26.5 .9 \pm 4.0$ years.

Majority of the cesarean sections in both the groups (Emergency and Elective) were done in the age group $<30$ years with $82 \%$ in the Em-RCS group and $77.1 \%$ in the El-RCS group.

The parity was two in $77.4 \%$ of women in Em-RCS and $75.1 \%$ of women in El-RCS. More number of women was booked in El-RCS (90.4\%) as compared to Em-RCS (87.8) (Table-1).

The overall any maternal morbidity of the women was found $1744(22.5 \%)$ among Em-RCS as compared to ElRCS 1117 (20.7). This difference in any morbidity was statistical significant $(\mathrm{P}=0.01)$. Blood loss was more than $1000 \mathrm{ml}$ in $476(8.8 \%)$ of El-RCS where as in Em-RCS it was $558(7.2 \%)$ (OR: 0.8, CI: 0.70-0.90, p=0.00 highly statistical significant).

Blood transfusion was $6.5 \%$ vs $7.5 \%$ in El-RCS and EmRCS respectively (OR: 1.15, CI: $1.00-1.33$, p=0.04, not significant). Dehiscence of scar in El-RCS was 119 $(2.2 \%)$ as compared to $367(4.7 \%)$ in EM-RCS (OR: 2.2, CI: $1.77-2.74, \mathrm{p}=0.00$ highly significant).

Post-operative/delivery complication was $313(5.8 \%)$ cases in El-RCS where as in Em-RCS was 458 (5.9\%) (OR: 0.98, CI: $0.84-1.14, \mathrm{p}=0.79$, not significant). Uterine rupture was $37(0.7 \%)$ in El-RCS where as in Em-RCS was 90 (1.2\%) (OR: 1.7 CI: 1.14-2.56, p=0.006 statistical significant (Table-2).

Maternal mortality was reported in $5(0.1 \%)$ cases of ElRCS as compared to $12(0.2 \%)$ cases in Em-RCS $(\mathrm{p}=0.37)$ which was not statistically significant.

The average duration of hospital stay for El-RCS was 10.6 \pm 5.0 days as compared to Em-RCS 10.3 \pm 3.5 .

The rates of admission to a neonatal intensive care unit was $11.2 \%$ vs $15.8 \%, \mathrm{p}=0.00$ statistical significant in ElRCS and Em-RCS respectively. 
Table 1: Characteristics of pregnant women undergoing emergency repeat cesarean section elective repeat cesarean section.

\begin{tabular}{|c|c|c|c|}
\hline Characteristics & $\begin{array}{l}\text { Emergency repeat cesarean section } \\
(\mathrm{N}=7752)\end{array}$ & $\begin{array}{l}\text { Elective repeat cesarean } \\
\text { section }(\mathrm{N}=5399)\end{array}$ & p-value \\
\hline \multicolumn{3}{|l|}{ Booking status } & \multirow{3}{*}{0.00} \\
\hline Booked & $6804(87.8)$ & $4883(90.4)$ & \\
\hline Unbooked & $948(12.2)$ & $516(9.6)$ & \\
\hline \multicolumn{3}{|l|}{ Referral status } & \multirow{3}{*}{0.00} \\
\hline Referred & $685(12.7)$ & $1474(19.0)$ & \\
\hline Non-referred & $4714(87.3)$ & $6278(81.0)$ & \\
\hline \multicolumn{3}{|c|}{ Place of residence } & \multirow{5}{*}{0.00} \\
\hline Rural & $3204(41.3)$ & $2443(45.2)$ & \\
\hline Urban slum & $1252(16.2)$ & $582(10.8)$ & \\
\hline Urban & $3296(42.5)$ & $2374(44.0)$ & \\
\hline \multicolumn{3}{|c|}{ Maternal age (Years) } & \\
\hline$\leq 19$ & $67(0.9)$ & $40(0.7)$ & \multirow{6}{*}{0.00} \\
\hline $20-24$ & $3097(40.0)$ & $1747(32.4)$ & \\
\hline $25-29$ & $3183(41.1)$ & $2377(44.0)$ & \\
\hline $30-34$ & $1111(14.3)$ & $962(17.8)$ & \\
\hline$>=35$ & $294(3.8)$ & $273(5.1)$ & \\
\hline Mean \pm Sd & $25.9 \pm 3.9$ & $26.5 \pm 4.0$ & \\
\hline \multicolumn{3}{|l|}{ Parity } & \multirow{6}{*}{0.00} \\
\hline 2 & $6001(77.4)$ & $4055(75.1)$ & \\
\hline 3 & $1420(18.3)$ & $1121(20.8)$ & \\
\hline 4 & $260(3.4)$ & $162(3.0)$ & \\
\hline 5 & $45(0.6)$ & $40(0.7)$ & \\
\hline$>5$ & $26(0.3)$ & $21(0.4)$ & \\
\hline \multicolumn{3}{|c|}{ Period of Gestation (weeks) } & \multirow{4}{*}{0.00} \\
\hline$<37$ weeks & $1453(19.3)$ & $841(15.8)$ & \\
\hline$\geq 37$ weeks & $6091(80.7)$ & $4480(84.2)$ & \\
\hline Not known & 208 & 78 & \\
\hline \multicolumn{3}{|c|}{ Infant's birth weight } & \multirow{7}{*}{0.00} \\
\hline$<2500$ & 1199 (19.2) & $732(13.6)$ & \\
\hline 2500-2999 & $2567(41.2)$ & $2125(39.4)$ & \\
\hline $3000-3499$ & $1819(29.2)$ & $1809(33.5)$ & \\
\hline $3500-3999$ & $543(8.7)$ & $490(9.1)$ & \\
\hline$\geq 4000$ & $59(0.9)$ & $67(1.3)$ & \\
\hline Not known & 43 & 176 & \\
\hline
\end{tabular}

Table 2. Morbidity in pregnant women undergoing emergency repeat cesarean section elective repeat cesarean section.

\begin{tabular}{|lccll|}
\hline & $\begin{array}{l}\text { Emergency repeat } \\
\text { cesarean section } \\
(\mathrm{N}=7752)\end{array}$ & $\begin{array}{l}\text { Elective repeat } \\
\text { cesarean section } \\
(\mathrm{N}=5399)\end{array}$ & $\begin{array}{l}\text { Odds ratio } \\
(\mathbf{9 5 \%} \mathrm{CI})\end{array}$ & p-value \\
\hline Any morbidity & $1744(22.5)$ & $1117(20.7)$ & $0.90(0.82-0.98)$ & 0.01 \\
\hline Anaesthetic complication & $71(0.9)$ & $46(0.9)$ & $1.08(0.73-1.59)$ & 0.71 \\
\hline Complication during surgery & $330(4.3)$ & $145(2.7)$ & $1.61(1.31-1.98)$ & 0.00 \\
\hline Dehiscence of the scar & $367(4.7)$ & $119(2.2)$ & $2.2(1.77-2.74)$ & 0.00 \\
\hline Uterine rupture & $90(1.2)$ & $37(0.7)$ & $1.7(1.14-2.56)$ & 0.006 \\
\hline Blood loss $>1000 \mathrm{ml}$ & $568(7.3)$ & $487(9.0)$ & $0.8(0.70-0.90)$ & 0.00 \\
\hline Broad ligament hematoma & $25(0.3)$ & $13(0.2)$ & $1.34(0.65-2.76)$ & 0.39 \\
\hline Blood transfusion & $578(7.5)$ & $353(6.5)$ & $1.15(1.00-1.33)$ & 0.04 \\
\hline Hysterectomy & $29(0.4)$ & $10(0.2)$ & $1.60(1.09-2.36)$ & 0.01 \\
\hline Post-operative complication & $458(5.9)$ & $313(5.8)$ & $0.98(0.84-1.14)$ & 0.79 \\
\hline
\end{tabular}




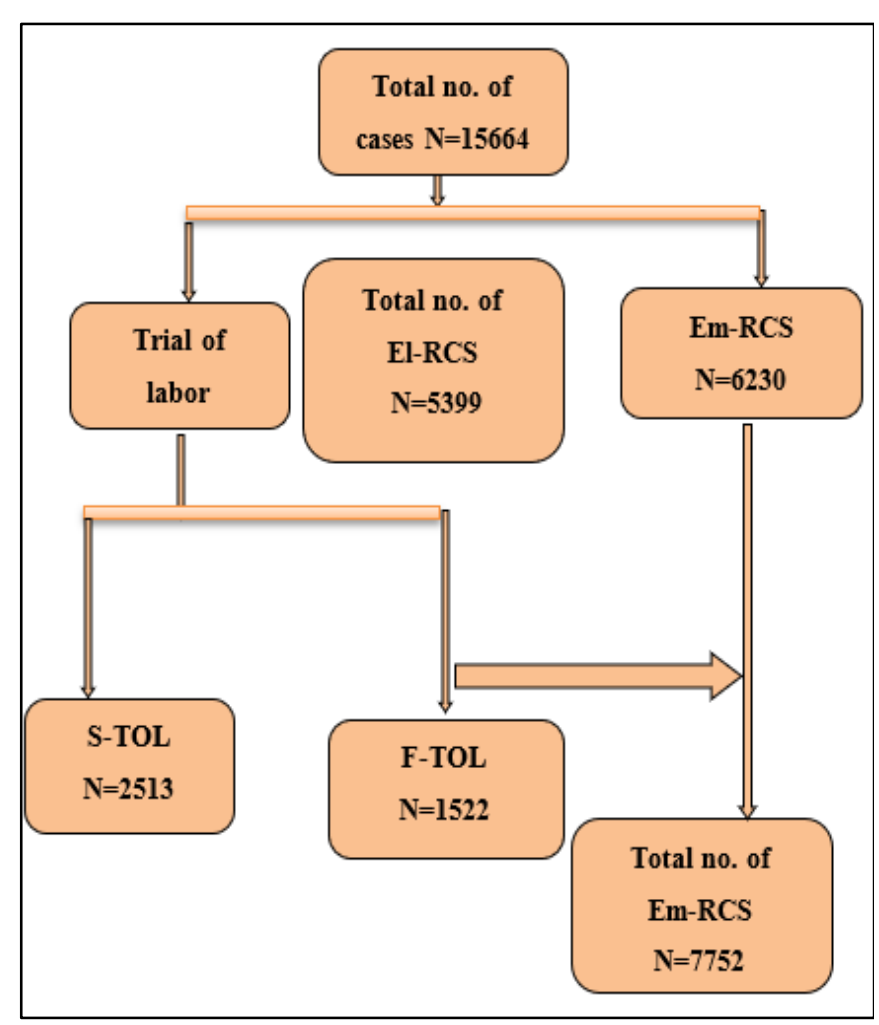

Figure 1: Diagrammatic representation of the selection of the study population.

\section{DISCUSSION}

Over the past decade there has been a gradual increase in the rate of cesarean section even in the developing countries causing considerable professional concern.

A total of 155863 deliveries took place in this study duration, out of which 43824 were the number of cesarean section and 15664 were the number of previous cesarean section the rate of cesarean section was $28.1 \%$ in this study out of which the Em-RCS rate was $7752 / 15664(49.5 \%)$ and El-RCS rate was 5399/15664 $(34.5 \%)$.

The high rate is because of the reason that these hospitals are a tertiary care which makes it a referral for various high-risk pregnancies.

Most of the cesarian sections were done in the age group of $20-29$ years $(81 \%$ and $76 \%$ in Em-RCS and ElRCS respectively) comparable to the study of Asifa Ghazi et al., and DA Vaughan et al., Anaesthetic complication seen in both the groups same which contributed to $0.9 \% .^{6,7}$

The difference was not statistically significant which was comparable to Suja Daniel et el. ${ }^{8}$ The main morbidity were complication during surgery, dehiscence of the scar, uterine rupture, blood transfusion and hysterectomy which were statistically significant. In present study the average duration of hospital stay for El-RCS was
10.6 \pm 5.0 days as compared to Em-RCS 10.3 \pm 3.5 which was statistically non-significant. and Al Nuiam et al., reported that $36.5 \%$ of emergency group stayed for more than 7 days and $39.8 \%$ of elective cases and duration of hospital stay for more than 7 days in emergency caesarean section was in $44.4 \%$ and for elective caesarean section $65.6 \%$ with $\mathrm{p}<0.001 .^{9,10}$

In the present study, the rates of admission to a neonatal intensive care unit was $15.8 \%$ versus $11.2 \%, \mathrm{p}=0.00$ statistical significant in Em-RCS and El-RCS respectively. In a study of Daniel $\mathrm{S}$ et al in which NICU stay was required in $39.4 \%$ of emergency cesarean sections as compared to $10.5 \%$ of elective cesarean. ${ }^{11}$

Emergency cesarean section was associated with significantly more maternal morbidity and mortality and neonatal outcome as compared to elective cesarean section. More research is needed to understand the health effects of cesarean section on immediate and future outcome.

\section{CONCLUSION}

Maternal morbidity was found more in emergency repeat cesarean section than in elective repeat cesarean section. Complications and referral of women who are likely to undergo cesarean section should be diagnosed at an early stage so that the maternal morbidity and mortality can be prevented.

\section{Principal co-investigators (in alphabetic order)}

Bharti S., Egmore, Chennai; Bhatia P., Kasturba Hospital, New Delhi; Coyaji K.J., KEM Hospital, Pune; Das M.C., Guwahati Medical College, Guwahati; ; Das V., CSMM University, Lucknow; Davar R.G., Sir J.J. Group of Hospital, Bombay; Devambigai S., Govt. RSRM Hospital, Chennai; Ganguly G., MLN Medical College, Allahabad; Ghosh T.K., P.G.I.M.E.R. \& SSKM Hospital, Calcutta; Gopalan S., PGIMER, Chandigarh; Idnani R., LLRM Medical College, Meerut; Kochar S., S.P.Medical College, Bikaner; Kodkany B.S., JLN medical college, Belgaum; Madhini V., Govt. K.G.Hospital, Chennai; Mittal S., AIIMS, New Delhi; Mukherjee J., R.G.Kar Medical College, Calcutta; Naphade P.R., B.J. .Medical College, Pune; Nevrekar P., Goa Med College, Goa; Padmanaban I., Kilpauk Medical College, Chennai; Pagi S.L., SSGS Medical College, Baroda; Patnaik S., SCB Medical College, Cuttack; Rajarajeswari S., Madurai Medical College, Madurai; Salhan S., Safdarjung Hospital, New Delhi; Salvi V., K.E.M. Hospital, Bombay; Sanghamitra M., Eden Hospital, Calcutta; Sharma S., Patna Medical College, Patna; Sharma S., SMGS Hospital, Jammu; Soni I.J.K., GSVM Medical College, Kanpur; Sulekha P.B., SAT Medical College, Thiruvanathapuram; Taly A., SMS Medical College, Jaipur.

\section{Funding: No funding sources}


Conflict of interest: None declared

Ethical approval: The study was approved by the Institutional Ethics Committee

\section{REFERENCES}

1. Choudhury CR. Caesarean births: the Indian scenario. Population Association of America 2008; $1-18$.

2. Sachs BP. Vaginal birth after caesarean. A heath policy perspective. Clin Obstet Gynaecol. 2001; 44:553-60.

3. Elvedi-GV, Klepac-PT, Peter B. Maternal and fetal outcome in elective versus emergency caesarean section in a developing country. Coll Antropol. 2006;30:113-8.

4. Joyce AM, Brady EH, Stephanie JV. Michelle JK Osterman MHS, TJ Mathews, Nat Vital Stat Rep. 2013;62

5. Pomela J, Harmesh B, Vidhushi B, Annika J. A Comparison of maternal and fetal outcome in elective and emergency caesarean sections. Indian Obstet Gynaecol. 2012;2:8-11.

6. Asifa G, Farha K, Ayesha MH, Tehmina A, Shazia J, Maternal morbidity in elective versus emergency at tertiary hospital; J Ayub Med Coll Abbott 2012:24:10-3
7. Vaughan DA, Cleary BJ, Murphy DJ. Delivery outcomes for nulliparous women at the extremes of maternal age- a cohort study. BJOG. 2014;121:261-8

8. Suja D, Manjusha V, Simi BN, Nazeema A. Study of Maternal Outcome of Emergency and Elective Caesarean Section in a Semi-Rural Tertiary Hospital; Natl J Med Res. 2014; 4:14-8.

9. Al Nuaim L, Soltan MH, Khashoggi T, Addar M, Chowdhury N, Adelusi B. Outcome in elective and emergency cesarean sections: A comparative study; Ann Saudi Med. 1996;16:645-9.

10. Gandhi K., Dahiya K., Gandhi K. Maternal and neonatal outcome in 1000 caesarean sections; International J. Healthcare Biomed Res, 2017:05:123-34

11. Daniel S, Viswanathan M. Study of maternal outcome of emergency and elective caesarean section in a semirural Tertiary hospital. Natl J Med Res. 2014;4:14-8

Cite this article as: Dhillon BS, Chandhiok N, Rao MVV. Is emergency cesarean section more risky than elective cesarean section in women with previous cesarean section?. Int J Reprod Contracept Obstet Gynecol 2018;7:1880-4. 